Comparative Philosophy Volume 11, No. 2 (2020): 113-139

Open Access / ISSN 2151-6014 / www.comparativephilosophy.org

https://doi.org/10.31979/2151-6014(2020).110208

\title{
WHAT KIND OF AN ILLUSION IS THE ILLUSION OF SELF
}

\author{
KARSTEN J. STRUHL
}

\begin{abstract}
Both early and later forms of Buddhism developed a set of arguments to demonstrate that the self is an illusion. This article begins with a brief review of some of the arguments but then proceeds to show that these arguments are not themselves sufficient to dispel the illusion. It analyzes three ways in which the illusion of self manifests itself - as wish fulfillment, as a cognitive illusion, and as a phenomenal illusion (what might be called the "I" sense). With respect to this last, the article reviews some recent developments in cognitive neuropsychology and neuroscience to discuss the way in which the phenomenal illusion of self is encoded within our brain processes. This article also considers the way in which the illusion of self is constructed through social interaction, by episodic memory, and by narrative construction. Finally, it focuses on how the illusion of self developed as an evolutionary necessity to make it possible for the human organism to navigate physical and social reality; and that it continues to be useful today. This poses a dilemma for the Buddhist soteriological project of extinguishing the illusion of self. Specifically, while it is possible to develop a non-self perspective though the continued practice of vipassanā (mindfulness meditation), it is not possible to maintain it consistently. The article concludes that even fully enlightened individuals must sometimes oscillate between a non-self perspective and a self-perspective and suggests an analogy between this oscillation and what occurs in the Kanizsa square illusion.
\end{abstract}

Keywords: Buddhism, illusion of self, neuropsychology, no-self, phenomenal self model, vipassanā (mindfulness meditation)

We all know the power of visual illusions to trick the mind into perceiving things incorrectly, but the most powerful illusion is the sense that we exist inside our heads as an integrated, coherent individual or self $(\operatorname{Hood} 2012,3)$.

Buddhist thought about the self and about self-consciousness is grounded in the idea that we are subject to profound cognitive illusions, and one of those is that we are distinct selves (Garfield 2018, 294).

STRUHL, KARSTEN J.: Lecturer of Philosophy, New School for Public Engagement \& City University of New York, USA. Email: kastruhl@tiac.net 
Belief in a self is deeply implicated in some of our most fundamental cognitive and affective structures (Siderits 2015, 46).

While there are many different schools of Buddhism and a number of disagreements even within each school, all of them endorse the doctrine of no self (anatta). The doctrine of no self claims that the view that the self exists is not simply a false idea but a fundamental illusion which is the underlying basis for suffering ( $d u k k h a)$ and whose dissolution is necessary for enlightenment/awakening. In this article, I want to develop an analysis of what it means for the self to be an illusion, how that illusion is constructed by both our cognitive and our affective habits of mind, and the extent to which it is really possible to extinguish that illusion of self. I will, however, also consider some possible objections to my analysis.

\section{WHAT IS THE IDEA OF THE SELF THAT IS BEING DENIED BY BUDDHISM?}

It is important to say at the outset that Buddhism is not denying that there exists a self in any sense of the term. "The Buddha never said that there is no self, only that the self is a mistaken interpretation of experience" (Olendzki 2016, 41). As we shall see, the root of this "mistaken interpretation" exists on a number of levels but involves mistaking a set of impermanent processes for a permanent thing. "Gotama no more rejected the existence of the self than Copernicus rejected the existence of the Earth. Instead, rather than regarding it as a fixed, non-contingent point around which everything turned, he recognized that each self was a fluid, contingent process just like everything else" (Batchelor 2011, 133). As we shall see, this fluid contingent process is, in fact a set of interacting contingent processes, and, in order to avoid confusion, I think it is better to use the term "person" for the sum of these processes.

In any event, in contrast to the idea of the "self" or person as a set of fluid, contingent processes, the view of the self that is being denied is the view that takes the self to have at least the following characteristics:

- The subject of experience which observes my experiences and is yet distinct from them; it is the first-person perspective;

- The substance self which underlies the psychophysical processes that constitute the person;

- The essential core of the person which makes me who I am; this core contains the essential properties of the substance self which constitute me as the subject of my experience;

- A permanent self that remains the same even as all my mental and physical properties change over time; thus, the essential core of the person does not change;

- An ownership self that possesses all the psychophysical processes; it is the possessor of my experiences and of my body; 
- An independent self that, although it interacts with other individuals, is ontologically distinct from them;

- A unitary self that unifies the elements of the person, both synchronically and diachronically into a single whole; the self is one, not many;

- An agent, an executive self that is capable of controlling both my actions and mental processes; it is sometimes called the CEO self;

- A bounded self which creates a duality between what is me and what is not me, between myself and others.

These various features are interwoven into our general concept of the self. Thus, what is being denied by Buddhism is the existence of a substantial, unchanging, independent and unitary entity with an essential core which is both the subject and possessor of my experiences and body, while yet distinct from them, which separates what is me from what is not me, and which is also the agent that controls my actions, desires, and thoughts. The belief that we have such a self is for Buddhism, a cognitive illusion. I will soon discuss the way in which this cognitive illusion is bound up with an illusion that functions at the phenomenal level - an intuition or feeling that all of what appears to consciousness is mine, that it is observed and controlled by me, an intuition which may be called the "I" sense or the phenomenal sense of self; or more simply, the phenomenal self.

\section{ARGUMENTS FOR NO-SELF}

Before proceeding further, it is important to be clear about why Buddhism claims that the self, as defined above, does not exist. The idea of the self that is denied by Buddhism is based on a soteriological project, a project which seeks to free us from $d u k k h a$, often translated as suffering, but which is better understood as a sense of unsatisfactoriness which pervades human life as it is ordinarily lived, an existential unease which continues to exist even in moments of pleasure and joy. For Buddhism, the proximate cause of this suffering is craving and attachment, but this is, in turn, generated by the belief in the self as defined above. Thus, the possibility of freeing ourselves from dukkha requires that we extinguish this belief and whatever illusions are bound up with it, that we extinguish the illusion of self. ${ }^{1}$ To do this requires both philosophical analysis and argument and meditative practice.

In this section, I want to focus on the philosophical arguments. The claim that the self as defined above does not exist rests on what can be called the reductionist strategy. This strategy reduces the person to a set of psychophysical processes, which Buddhism

\footnotetext{
${ }^{1}$ Freeing ourselves from dukkha is understood as the attainment of Nirvana, which literally means "to extinguish." What is extinguished is dukkha, the cravings and aversions which bring it about, and the illusion of self from which the cravings and aversions arise. In so doing, what is extinguished is also the "fires" of greed (lobha) or lust (raga), hatred (dosa), and ignorance or delusion (moha). These are the poisons, the roots of unwholesome actions that are the proximate causes of both individual and social suffering.
} 
called skandhas, or aggregates. The early Buddhism of the Pāli Canon² grouped these processes into five aggregates: material form (rüpa), which refers to all matter but

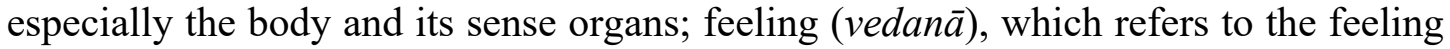
quality of sensations as pleasant, unpleasant, or neutral; perception (sañña), which refers to the judgment that recognizes objects and categorizes them; mental or volitional formations (sankhāra), which refers to all mental constructions including thoughts, intention, emotions, desires, and wishes; and consciousness (viñ̃āna), which is the awareness of physical and mental objects. The Pâli Canon then proceeds to examine each of these aggregates separately and, in what may be called the criterion argument, argues that none of them can be a self either separately or collectively. There are two criteria for something to qualify as a self that are emphasized in this argument. The first is the criterion of permanence which cannot be fulfilled, since, for Buddhism, everything is impermanent, and this includes the psychophysical processes that constitute the person. The Pâli Canon argues that none of the aggregates either individually or collectively are permanent. Questions like the following are asked. Is the body or our physical processes a self? Are our sensations and feelings a self? Are our thoughts, intentions, or desires a self? Is our awareness of these processes a self? The answer to all these and other similar questions is no, since each of these physical or mental processes is constantly changing. They cannot be a self, as one of the basic criteria for being a self is that it be permanent. The question is then asked, can the totality of these processes be a self. But here again, the answer is no, since the totality of these physical and mental processes are constantly changing. Thus, since part of what it means to be a self is that the entity in question be permanent, the totality of these processes cannot be a self. The second criterion that is advanced in this argument is the criterion of control. For the self to be an agent, for it to be an executive control center, it must be capable of controlling each of the aggregates. But again none of the aggregates either separately or collectively is subject to control. We cannot control the processes that arise in either the mind or the body. Thus, here again, none of the aggregates either separately or collectively can be a self.

If these arguments are correct, they establish that none of the aggregates is a self and that the aggregates collectively cannot be a self. However, these arguments alone could not establish that there is no self, since the self could in principle be something beyond the aggregates, something which is permanent and which controls the aggregates but which is not itself one of the aggregates, something that is a possessor and observer of the aggregates but not itself the aggregates. In traditional Brahmanic thinking, this is the atman, the true self, something which transcends the aggregates

\footnotetext{
${ }^{2}$ The Pāli Canon, named for the language in which it was written, consists of three large sets of texts known as the Tipitaka ("three baskets"). The first set of texts is the Vinaya Pitaka the rules and regulations prescribed for monastics. The second is known as the Sutta Pitaka and contains suttas (verses) grouped into five large collections known as Nikayyas (discourses). The third is the Abhidamma Pitaka which was written after the Buddha's death and is an attempt to develop a systematic Buddhist philosophy. The five Nikayas purport to record the dialogues between the historical Buddha and other persons, often his disciples, and sometimes between his disciples. They are generally regarded as the most authoritative record of the teachings of the historical Buddha.
} 
and which is the permanent observer and controller of them. Thus, in order for the Buddhist argument to establish that there is no self, it must make an additional claim which is sometimes called the exhaustiveness claim, the claim that every aspect of the person is accounted for by the five aggregates, that the person is nothing more than the five aggregates. If this claim is correct, then in conjunction with the arguments above, it would establish that while there are persons, they are empty of self. ${ }^{3}$

If there was something more to the person than the five aggregates, this would need to be established by direct observation or by inference. But surely, as Western philosophers like David Hume noted, we do not through introspection directly observe a self which is separate from the stream of our experiences. The only possibility, then, of affirming such a self is through inference. Such an inference would take the form of arguing that while the self cannot be directly perceived within experience, it is something which we must assume in order to account for certain aspects of our experience. One of the main forms of inference which is thought to establish the existence of a self as transcendent to our psychophysical processes arises from the need to explain the apparent continuity of the stream of experiences. If there is no substantive agent behind the stream, what is it that keeps the stream going? What keeps the stream of mental and physical processes going over time? The Buddhist answer is to be found in the doctrine of dependent origination (dependent arising or dependent co-arising). ${ }^{4}$ This doctrine maintains that all phenomena are dependent for their existence on other phenomena in a complex causal chain. Everything that exists is dependent for its existence on other things that exist. Therefore, each of the mental and physical processes that constitute the person arises as the causal result of other mental and physical processes. For example, the thought I have now was brought about by previous thoughts or by some sensation, desire, or emotion; that thought may also bring about certain new desires or emotions, which will, in turn, bring about still other thoughts, desires, or emotions; and so on. In other words, the stream is kept going by the causality of the processes themselves. Thus, to explain the stream, there is no need to posit an "I" behind the stream that keeps it going. There is no "selfing" glue which binds our mental and physical processes together over time. "There is no unmoving mover behind the movement. It is only movement....there is no thinker behind the thought. Thought itself is the thinker. If you remove the thought, there is no thinker to be found" (Rahula 1974, 26). The same holds of any other set of physical or mental processes.

A related problem is the problem of diachronic unification - why a multiplicity of mental states over time is all taken to be mine. How, for example, is the memory image that I have at the moment related to the perception in the past which I remember? How does the memory of the pleasure which an object gave me in the past engender a desire

\footnotetext{
${ }^{3}$ This needs some clarification. The Buddhist analysis of no-self does not claim that there are no persons but rather that there is nothing within what we call the person which can be called a self. Thus, the point of saying that the person is empty of self is that (a) the totality of these psychophysical processes cannot be a self and (b) that there is no additional entity beyond them to which the term "self" could accurately refer.

${ }^{4}$ These are the usual translations of the Pāli term pațicca samuppāda.
} 
for that object when I encounter that object in the present? Does this not require a unifying observer, a unifying subject of my experiences which persists over time? Here again, the doctrine of dependent origination provides the answer. Perceptions, memories, and desires that are "mine" are part of a complex causal series. Thus, the Buddhist answer to the problem is that "the need for an observer self that fuels the diachronic unification argument is the product of a powerful illusion fostered by our use of the convenient designator 'person.' The key...is the notion of a causal series. They [Buddhist Reductionists] maintain that what is conventionally called a person is in fact a causal series of impersonal, impermanent psychophysical processes" (Siderits $2015,37)$. The point of saying that the term "person" is a conventional designation is that we have as a matter of social convention a single term, a noun, which refers to the totality of psychophysical processes which are causally related both synchronically and diachronically. We, then, assume that the use of the term "person" entails that there is a single entity to which the term refers. In effect, we hypostatize the term. We take the abstract noun "person" to refer to a single concrete reality. I shall have more to say later about the way which our language constructs the cognitive illusion of the self.

Thus, the idea that there is an entity over and above the psychophysical processes that constitute the person is not necessary to explain the continuity of these processes or the diachronic unification of a multiplicity of different mental states. Nor can such an entity be directly observed. While this does not in itself prove that there could be no such entity, the arguments above, if correct, can at least claim to have demonstrated that the postulation of a subject of experience which is transcendent to the aggregates is unnecessary; that it is unnecessary to posit a substantive agent to explain what keeps the stream of experience going. We can, then, employ the principle of lightness, classically known as Occam's razor. The principle of lightness holds that the best explanation for a range of phenomena is to have as few entities as necessary to explain the problems posed by the phenomena. In other words, a theory developed to explain some range of phenomena should not multiply entities beyond what is necessary to explain the phenomena. Thus, if the person and the apparent continuity of consciousness can be explained without positing a self, it is reasonable to assume that there is no self. Positing a self would simply be positing an additional entity for which there is no need. The reasonable conclusion, then, is that the self does not exist and, therefore, that the belief that there is such a self is a false belief. But is this false belief also an illusion?

If the problem of the self were simply the problem of having a false belief, then philosophical argumentation should be sufficient to dispel it; and it would then follow that with sufficient philosophical investigation the suffering from which the Buddhist soteriological project begins would be extinguished. However, it is readily acknowledged that while philosophical analysis and argumentation may prepare the ground for making the Buddhist doctrine of no-self credible, it will not be sufficient. This is because the belief that each of us has within us a self which is permanent and ontologically separate from others and from the world is based on a "primal confusion" that "is more like [an] optical illusion than like [a] misguided metaphysics" (Garfield 
$2015,10)$. In other words, the false belief that there is a self is not just a false belief but an illusion.

\section{WHAT IS AN ILLUSTION? \\ IN WHAT WAYS MIGHT THE SELF BE CONSIDERED AN ILLUSION?}

An illusion is not simply a false belief, although some false beliefs are illusions. Let me then begin with Freud's claim that "we call a belief an illusion when a wishfulfillment is a prominent factor in its motivation, and in doing so we disregard its relation to reality" (Freud 1989, 40). In this sense, the function of the belief is to satisfy some basic wishes or desires. ${ }^{5}$ From this it follows that a belief which is an illusion in Freud's sense of the term will strongly resist any arguments or evidence to the contrary. However, Freud does acknowledge that "illusions need not necessarily be false - that is to say, unrealizable or in contradiction to reality" (Freud 1989, 39). ${ }^{6}$ Thus, even if the belief in the existence of the self were true, it would still count as an illusion so long as it is motivated primarily not by evidence or argument but by wishes that the belief satisfies.

While illusions in Freud's sense of the term might not be false, there are two other senses of illusion which claim that they entail a significant misrepresentation of reality. The first of these are beliefs which are so interwoven with our thinking that they are simply taken for granted. These are properly speaking "cognitive" illusions, and might be also called "metaphysical" illusions in that they are beliefs about the fundamental nature of reality. Such cognitive or metaphysical illusions may be susceptible to reason but are nonetheless difficult to dislodge. If the belief in the self is a cognitive illusion, then even credible philosophical arguments against its existence will be strongly resisted; and even if the arguments are accepted intellectually, the belief will tend to reassert itself.

The second way in which an illusion may produce a misunderstanding of reality may be called a "perceptual" or "phenomenal" illusion in that what exists appears differently than what it is. Perceptual or phenomenal illusions are not themselves beliefs, although they often lead us to accept certain beliefs. They, therefore, cannot be dispelled by philosophical argument alone. They can, however, be seen to be illusions through careful experiential examination. For example, in the Kanizsa square illusion (Figure 1 below), drawing one's attention to the space between any of the black objects makes it clear that there are no lines between them and, therefore, that the appearance of the square is an illusion. Nonetheless, as soon as one moves back from this close

\footnotetext{
${ }^{5}$ Freud, of course, takes these wishes or desires to reside in the unconscious mind. However, Freud's general definition of illusion can be accepted without the endorsement of his theory of the unconscious. On the other hand, I do think that for a belief to be primarily motivated by wish or desire requires that the desire be not conscious in some sense, as otherwise it would be difficult to disregard evidence or arguments that ran counter to it.

${ }^{6}$ Freud distinguishes an illusion from a delusion in that the latter is necessarily "in contradiction to reality." While the boundary line between the two is not always clear, Freud suggests as an example that the alchemist illusion that gold could be created from base metals might, in fact, turn out to be true.
} 
attention, the illusion of the square reappears. Given the way our mind naturally structures our perceptions, it fills in the spaces between the black objects, creating the illusion of a square which does not exist. As a result, it is not possible to make the square disappear even when we know that it does not exist. Thus, if the self is a phenomenal illusion, it should be an illusion based on the way our mind naturally structures our experience, but it should also be capable of being seen as an illusion by careful experiential examination. As we shall see, such examination will require more than ordinary introspection. It will require special meditative techniques.
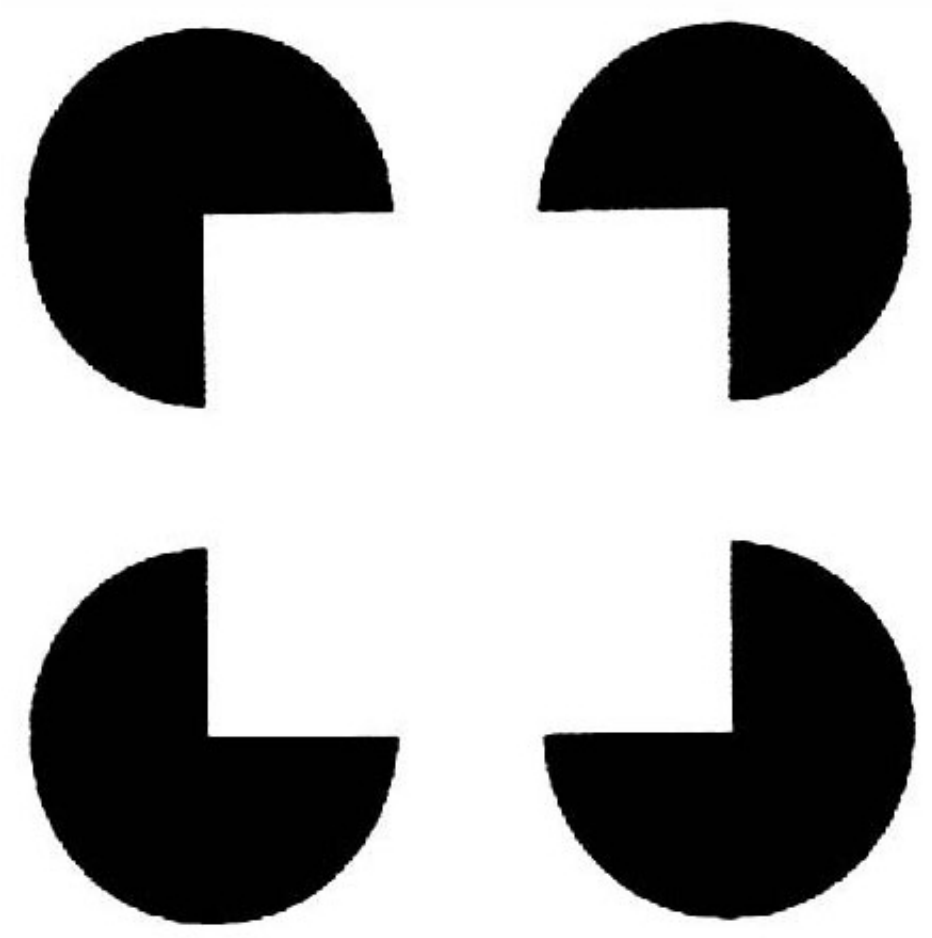

FIGURE 1: The Kanizsa Square Illusion

While analytically, it is useful to keep the three senses of illusion separate, they will in practice often be conjoined. Beliefs motivated by strong wishes are often strongly supported by cognitive illusions, and such cognitive illusions are often generated by basic intuitions or feelings based on the way our mind organizes our experiences. Thus, if the self is an illusion, the belief that it exists may be derived from basic human wishes, reinforced by beliefs that are cognitive illusions, and grounded in our phenomenal intuition of self, what may be called our "I" sense, that cannot be dissolved without the aid of special meditative techniques. 


\section{THE SELF AS WISH-FULFILLMENT, AS COGNITIVE ILLUSION, AND AS PHENOMENAL ILLUSION}

I now want to consider in some detail how the illusion of self exists in the three forms discussed above. I will begin with the illusion of self as a wish fulfillment. While there may be, of course, a number of different kinds of wishes that are bound up with the belief in the existence of the self, I would suggest one that has a universal appeal. This is the wish that for continued existence, for immortality, for eternal life; and this wish is closely connected with a second wish - the wish for some universal being or force that would protect us from harm. "Two ideas are psychologically rooted in man: selfprotection and self-preservation. For self-protection man has created God....For selfpreservation man has conceived the idea of an immortal soul, or Atman, which will live eternally. These ideas are so deeply rooted in man...that he does not want to hear...any teaching against them" (Rahula 1974, 51-52). In Judeo-Christian-Islamic thought, these two wishes converge insofar as God creates and guarantees the continued existence of the soul; in Brahmanic thought, the claim that the Atman is the Brahman, the ultimate foundation of the universe, guaranties that one's true self cannot perish. Furthermore, the wish that life does not end with death is also motivated by the general goal of human happiness insofar as that goal is bound up with the attempt to give one's life meaning and purpose as a whole, a meaning and purpose which go beyond and situate our specific projects in the more encompassing project of human happiness. Belief in the self gives one the sense of being the narrator and central character of one's life and, therefore, gives one's life events a sense of a larger meaning and purpose. But this, in turn, requires that this "self" be open continuously to the future. Without such a central character, the more general goal of human happiness seems insubstantial and transient. ${ }^{7}$

The belief that there is some core essential self that persists throughout our lives is also an illusion in the second sense discussed above, as the belief seems to be so interwoven into our thinking about ourselves that it is taken for granted and arguments to the contrary will be strongly resisted. In this sense, the belief that we have such a self is a cognitive illusion. I suggest that there are at least four interrelated factors that make it a cognitive illusion - the subject-predicate form of our language, the use of certain terms as convenient designators, our tendency to hypostatize and essentialize, and our use of indexical expressions.

Our subject-predicate language creates sentence structures in which the subject as noun or pronoun is separate from the action designated by the verb. "Nouns...are a shared convention of language which artificially creates islands of meaning upon a constantly shifting sea of becoming....Any time that we use self in a sentence...we are forced into using it as an agent noun....In short, self is a noun that cannot be verbed" (Olendzki 2016, 112). Thus, we take the "self" to be a subject separate from the processes to which it is connected and an entity which initiates and controls these

${ }^{7} \mathrm{I}$ am indebted to Mark Siderits for this argument. "Realizing one's mortality radically undermines this [happiness-seeking] enterprise. The difficulty is not just that my present projects come to seem parochial and thus trivial... [but] that such projects derive their point from the larger happiness-seeking project in which we are engaged, and this requires that there be a self with an open future" (Siderits 2015, 46). 
processes. Closely allied to this is the convenient designator "person" which we tend to hypostatize. In other words, we represent the abstract noun "person" as if it were a concrete reality and believe that there must be some concrete entity within the person which is more than the changing psychophysical processes. ${ }^{8}$ Furthermore, when we classify and categorize, we tend to ignore the fact that our classifications are conventional, and we, therefore, assume that the things which we classify together have a real essence which is responsible for their being those kinds of things. Thus, when we use the term "person," we assume that there is some essential entity which is the core of the person, an entity which remains constant throughout the changes which the person undergoes. Finally, our use of the indexicals "I" and "me" suggests that when I say 'I think' or 'I feel', there must be an "I" which is separate from the thinking and the feeling, an "I" which controls and is responsible for the thinking, and a "me" which is separate from "you." 9

There is yet a deeper way in which the illusion of the self is manifested, and this is as a phenomenal or perceptual illusion. What appears in this illusion is an intuition or feeling whose appearance does not disappear even if the philosophical arguments are accepted and even if we are not under the sway of the cognitive illusion discussed above. My thoughts, feelings, emotions, intentions, desires, etc., are immediately experienced in the first-person perspective as mine. Here we may speak of the phenomenal self, a sense of self which is manifested pre-reflectively and perhaps even pre-linguistically, what I suggested earlier may also be called an "I" sense. Various strands of our phenomenal field interweave to construct the sense, intuition, or feeling of self - the sense of me being inside our body and, more specifically, my head, the feeling that I am distinct from others, the feeling that I can initiate and control my thoughts and actions, and the memory of myself having existed in the past.

I can look in the mirror and "see myself," but what I actually see is the part of my body reflected by that mirror. I, however, do not experience the reflection as simply my body, but see the reflection of my body as the reflection of some inner "me." This perceiving of my "self" is not an inference but an immediate apprehension of myself within my body. "When we look at the mirror, we see the outward appearance of our self but we believe that the image is simply the outer shell of the body we occupy. We believe there is so much more to our self on the inside" (Bruce Hood 2012, 292). Furthermore, this "I" is not experienced as something momentary which changes with the motions of my body but is experienced as continually within my head from where it moves the other parts of my body. "...whatever is part of your conscious Ego is endowed with a feeling of 'mineness,' a conscious sense of ownership..., a deeper sense of selfhood having to do with owning and controlling your body as a whole" (Metzinger 2009, 5).

\footnotetext{
8 "....it is difficult to resist the sense that we are aware of the self as something distinct from all empirically given content. The Buddhist Reductionist would explain this phenomenon as a result of hypostatization. And this... is induced by our use of the convenient designator 'person"' (Siderits 2015, 44).

${ }^{9}$ It used to be thought that when rain occurs, there was a god who is responsible for it. We, however, no longer think that the subject predicate form "it is raining" entails that there is an "it" which is raining.
} 
When I am thinking about what I will do next, I am aware that I am influenced by a variety of factors and often constrained not only externally but internally. Nonetheless, in wrestling with any decision, I feel myself as self-determining, able to decide which influences to follow or, through an effort of will, even to overcome these influences and internal constraints. In other words, while I can recognize the effects of certain causal forces, I experience myself as able to rise above them and choose to move against them. "If we take our own phenomenology seriously, we clearly experience ourselves as beings that can initiate new causal chains" (Metzinger 2009, 126).

When I remember something that happened in the past, I do not merely remember it as a past event but as something that happened to me. In fact, my sense that I exist over time is predominantly based on my memory of these events as having been experienced by me. This is episodic memory, and it is perhaps the most important factor in the constitution of the phenomenal self. "Several psychological factors...persistently reaffirm to the individual that there is an enduring self. Perhaps the most obvious of these psychological factors is episodic memory - memory of experiences. It's widely thought that when a person remembers an experience, she remembers the experience as having happened to her" (Garfield 2018, 290). It does not matter whether what I remember actually happened. What is important is that I see myself in those memories. Episodic memory may also be a bridge between the phenomenal illusion of self and the cognitive illusion of self, as there seems to be a close link between the raw memories of myself having done or experienced certain things and my reports in the first-person of those experiences. Episodic memory is also the basis for a narrative sense of self which I will discuss shortly.

I interact with various people throughout the day, and I sometimes recognize that my way of relating is different with a number of them. Nonetheless, although my roles may be different, I experience myself as being the same individual playing different roles and as distinct from the individuals with whom I interact. My experience of self in relation to others is not an inference but a direct apprehension of myself in relation to other persons. In fact, there is good reason to think that the phenomenal sense of self was initially constructed in the early stages of the child's life through interaction with parents or other caretakers. This is perhaps why we cannot remember what it was to be an infant, why episodic memory seems to begin at early childhood. ${ }^{10}$ I have more to say about this later when I discuss the social and narrative construction of the self illusion.

\section{THE NEUROPSYCHOLOGICAL CONSTRUCTION OF THE PHENOMENAL SELF}

I now want to consider what may be the underlying causes of the phenomenal self, the underlying causes which construct the sense of "I". More recent writing in the field of

\footnotetext{
10 "It's not that you have forgotten what it was like to be an infant - you simply were not "you" at that age because there was no constructed self, and so you cannot make sense of early experiences in the context of the person to whom these events happened" (Hood 2012, 75-76).
} 
neuropsychology has pointed to processes in the brain that generate what the German philosopher Thomas Metzinger ${ }^{11}$ refers to as a "phenomenal-self model" (PSM), and he claims that it is these processes which generates the illusion of self. To define the PSM, Metzinger discusses the rubber hand illusion. In this illusion, one of the hands of the subject is concealed from view, and she observes a visible rubber hand in front of her on the desk. The visible rubber hand and the subject's own concealed hand are then stroked simultaneously. What the subject experiences, according to Metzinger, is this: "Suddenly, you experience the rubber hand as your own.... What you feel in the rubberhand illusion is what I call the content of the phenomenal self-model (PSM) - the conscious model of the organism as a whole that is activated by the brain....The content of the PSM is the Ego" (Metzinger 2009, 3). Metzinger then argues that the PSM establishes the physical boundaries of the self, a body image which could be different, as evidenced in out-of-body experiences, ${ }^{12}$ and that without the PSM I would not experience the parts of my body or my mental processes as mine. "Only if you have a self-model can you experience your hands and your arms as parts of your own body. Only if you have a self-model can you experience certain cognitive processes in your brain as your own thoughts and certain events in the motor parts of your brain as your own intentions and acts of will" (Metzinger 2009, 115). The PSM is the illusion that conscious experience is "my" experience, that it is inside "my" body and, thus, is the center and owner of its experiences.

In order for this to happen, the brain creates both a model of the world and a model of oneself within the world. Metzinger explains this as follows:

First, our brains generate a world-simulation, so perfect that we do not recognize it as an image in our minds. Then, they generate an inner image of ourselves as a whole. This image includes not only our body and our psychological states but also our relationship to the past and the future, as well as to other conscious beings. The internal image of the person-as-awhole is the phenomenal Ego, the "I" or "self" as it appears in conscious experience....By placing the self-model within the world-model, a center is created. That center is what we experience as ourselves, the Ego. It is the origin of what philosophers often call the firstperson perspective (Metzinger 2009, 6-7).

Thus, the PSM is constructed as a first-person perspective centered within a virtual world. By exercising control in this virtual reality, I can effectively navigate my environment. ${ }^{13}$ However, our ability to navigate our environment requires that we not

\footnotetext{
${ }^{11}$ Thomas Metzinger is a German philosopher and phenomenologist who works closely with and whose writings are informed by cognitive and neuroscientists.

12 "Could one create a full-body analog of the rubber-hand illusion? Could the entire self be transposed to a location outside of the body? As a matter of fact, there are phenomenal states in which people have the robust feeling of being outside their physical body - these are the so-called out-of-body experiences, or OBEs" (Metzinger 2009, 5).

${ }^{13}$ Metzinger is not claiming that there is no reality other than the virtual reality, that what we call reality is only a subjective phenomenon. "Yes, there is an outside world and, yes, there is an objective reality, but in moving through this world, we constantly apply unconscious filter mechanisms, and in doing so, we unknowingly construct our own individual world, which is our 'reality tunnel'.... The filtering
} 
recognize the virtual reality as virtual. To make this point, Metzinger uses the analogy of a flight simulator.

The human brain can be compared to a modern flight simulator in several respects. Like a flight simulator, it constructs and continuously updates an internal model of external reality by using a continuous stream of input supplied by the sensory organs and employing past experience as a filter....For us, phenomenal reality is not a simulational space constructed by our brains....[I]t is the world we live in. Its virtuality is hidden, whereas a flight simulator is easily recognized as a flight simulator (Metzinger 2009, 107).

In order to exercise control in this virtual reality, the PSM is also constructed as an illusion of self as agent, of an executive control center, although there is, in fact, no agent controlling the show.

The self-model...binds the processes by which the mind creates and compares competing alternatives for action with feedback from your bodily movements. This binding turns the experience of movement into the experience of an action. But note, once again, that neither the "mind" nor the self-model is a little man in the head; there is no one doing the creating, the comparing, and the deciding. If the dynamical-systems theory is correct, then all of this is a case of dynamical self-organization in the brain (Metzinger 2009, 121).

It should be added that this "dynamic self-organization of the brain" is not a single process located in a part of the brain but a multiple set of brain processes. As the British developmental and cognitive neuropsychologist Bruce Hood puts it, "The brain has many distributed jobs.... [T] he sense of self that most of us experience is not to be found in any one area. Rather it emerges out of the orchestra of different brain processes like a symphony of the self, just as Buddha and Hume said" (Hood 2012, xii). However, brain processes alone do not construct the illusion of self.

\section{THE SOCIAL AND NARRATIVE CONSTRUCTION OF THE ILLUSION OF SELF}

The fully developed sense of self emerges out of the interplay between brain processes, social interaction, and narrative construction. "This development of the self emerges across childhood as the interplay between the modeling brain, constructing stories from experience, and the influences of other people" (Hood 2012, xiv). While the precise relation of these factors may be somewhat in dispute, there is, I think, little disagreement that human beings are a social species and that the desire for social interaction is an innate component of the human genome. This innate desire for sociality is organized by our brain processes and lays the foundations for the emergence of the sense of self. "The mind that generates our sense of self is a product of a brain

mechanisms are our sensory systems and our brain....[W]e see only what our reality tunnel allows us to see" (Metzinger 2009, 8-9). Thus, our internal representation of the world and the PSM make it possible to act effectively in the real world, but we know that world only through our representations of it. 
that has evolved to become social. But in being social, the self is radically altered by the presence of others and our need to fit in with them" (Hood 2012, 184). In fact, it may be more accurate to say that the emergence of the sense of self develops out of our interactions with others. George Herbert Mead has theorized this development nicely.

The self, writes Mead, is not something which is there from birth. What is there at birth is the human body with its desires, but the self can easily be distinguished from the human body. "The body can be there and can operate in a very intelligent fashion without there being a self involved in the experience....We can lose parts of the body without any serious invasion of the self' (Mead 1963, 136). For Mead, the self is something that emerges and is constructed through the individual becoming an object to herself. But how is this possible? "How can an individual get outside himself (experientially) in such a way as to become an object to himself?" (Mead 1963, 138).The answer Mead gives is that the individual can only see herself as an object by assuming the vantage point of another toward herself, since only the other can initially see her as an object. For the self to exist, I must stand outside myself and take the attitude of another toward myself, which is why, for Mead, the construction of the self is necessarily a social construction and, therefore, must incorporate the attitudes of others within myself. In short, the individual human organism develops a sense of self only when it learns to experience itself from the "particular standpoints of other individual members of the same social group, or from the generalized standpoint of the social group as a whole" (Mead 1963, 138). ${ }^{14}$

Once the sense of self has emerged, we can begin to communicate with others through language, and we can also begin to use language to think, which is itself initially an internalization of our communication with the other. With the emergence of the sense of self, episodic memory also emerges, and we begin to use language to create stories about ourselves, stories we tell to ourselves and to others. In so doing, we create narratives of our lives by piecing together certain episodic memories with a variety of distortions, some of which are fictitious elements which we (unconsciously) invent in order to tell a story which affirms our sense of self. In fact, much of episodic memory is already narrative construction, as the stories embodied in the memories helps to weave the memories together and to make sense of our experiences. "Memories are not recordings but stories we retrieve from the compost heap that is our long-term memory; we construct these stories to make sense of the events we have experienced" (Hood 2012, 220). As we construct these narratives, we give content to the illusion of self, and we further develop the illusion as the central character in a set of stories. The various stories that we tell about ourselves provide the scaffolding for the fully developed illusion of self, and, as these stories seem meaningless without a central character, they reinforce the illusion and make it difficult to extinguish. Thus, Bruce Hood suggests an analogy between the sense of self at the center of the narratives

\footnotetext{
${ }^{14}$ Mead's analysis often resonates in contemporary analyses of the construction of the sense of self. For example, Evan Thompson writes, "Indeed, being able to think of oneself as a self seems inseparable from being able mentally to grasp an outside view of oneself, that is, from the vantage point of the other" (Thompson 2015, 345).
} 
and the Kanizsa square illusion. "There is no self at the core. Rather, it emerges as the 'center of a narrative gravity.' In the same way that we can see a square at the center of the arrangement in [the Kanizsa square illusion], it is an illusion created by the surrounding elements" (Hood 2012, xiii). ${ }^{15}$

\section{THE EVOLUTIONARY DEVELOPMENT AND FUNCTION OF THE ILLUSION OF SELF}

If the sense of self is an illusion, then why did it develop in our species? To answer this question, we need first to recognize that the evolutionary development of a trait within a species need not track reality accurately. The grid of natural selection does not function to develop an accurate perception of reality but to perpetuate and proliferate the gene pool. As the evolutionary psychologist Robert Wright notes,

Genetically based traits that in the past contributed to genetic proliferation have flourished, while traits that didn't have fallen by the wayside. And the traits that have survived this test include mental traits - structures and algorithms that are built into the brain and shape our everyday experience. So if you ask the question "What kinds of perceptions and thoughts and feelings guide us through life each day?" the answer, at the most basic level, isn't "The kinds of thoughts and feelings and perceptions that give us an accurate picture of reality." No, at the most basic level the answer is "The kinds of thoughts and feelings and perceptions that helped our ancestors get genes into the next generation" (Wright 2017, $3-4)$.

Thus, that the self is an illusion does not negate its usefulness. It was useful to our ancestors, and in many ways it continues to be useful for us today. ${ }^{16}$ It is a device for directing our behaviors so that we can efficiently navigate both the physical and social world, and it is a device which can sometimes be turned off when it is not needed. "The Ego is a tool for controlling and planning your behavior and for understanding the behavior of others. Whenever the organism needs this tool, the brain activates a PSM. If - as, for instance, in dreamless deep sleep - the tool is not needed anymore, it is turned off' (Metzinger 2009, 8). The illusion of self also has an important internal function for the human organism. It evolved so that a multitude of experiences which would otherwise be fragmented could be bound together. It provides a focal point which allows a multitude of experiences to be organized into a coherent narrative.

\footnotetext{
${ }^{15}$ The idea of the self as the "center of narrative gravity" was first introduced by Daniel Dennett in his essay "The Self as a Center of Narrative Gravity" (Dennett 1992). For Dennett, the center of narrative gravity is the central character in the story. I, therefore, create the sense of self through creating myself as the central character in the stories that I tell.

${ }^{16}$ That an evolutionarily developed trait was useful to our ancestors does not entail that it is useful for us today. In fact, the opposite may be the case. "The modern environment can take various kinds of feelings that served our ancestors in this Darwinian sense and render them counterproductive....Violent rage and the yearnings of a sweet tooth are good examples. These feelings were once "true" at least in the pragmatic sense of guiding the organism toward behaviors that were in some sense good for it. But now they're likely to mislead" (Wright 2017, 40-41).
} 
Why did we evolve the self illusion? Like every other illusion our brain generates, it serves a useful purpose....Experiences are fragmented episodes unless they are woven together in a meaningful narrative. This is why the self pulls it all together. Without a focus, the massive parallel processing in our brain means that we would be overwhelmed by the sheer volume of computations if we ever had to deal with them individually" (Hood 2012, 290).

By creating the illusion that our experiences hold together coherently, the phenomenal self also creates the illusion that that we are coherent agents, and this has an important social as well as internal function, a social function which gave our species an evolutionary advantage in the struggle for survival. By thinking of ourselves as coherent agents, we also convince others that we are coherent agents; and this allows us to treat each other as morally responsible beings.

Why would natural selection design a brain that leaves people deluded about themselves? One answer is that if we believe something about ourselves, that will help us convince other people to believe it. And certainly it's to our benefit - or, more precisely, it would have been to the benefit of the genes of our hunter-gatherer ancestors - to convince the world that we're coherent, consistent actors who have things under control (Wright 2017, $81)$.

In all, the illusion of self also made it possible for us to develop fully as social beings, and with this development there emerged another form of evolution - cultural evolution. "The PSM of Homo sapiens is probably one of nature's best inventions....[I]t allowed biological evolution to explode into cultural evolution" (Metzinger 2009, 4-5). Thus, if the self is an illusion, it would seem to be a highly positive illusion. From an evolutionary point of view (both biological and cultural evolution) the illusion of self was a necessary illusion. Furthermore, there are good reasons to think that it still has some very useful, perhaps even essential functions. Why not, then, simply continue to act as if it existed, even if we are convinced philosophically that it does not exist.

We are now left with a dilemma for the Buddhism's soteriological project. Buddhism insists that the illusion of self is the ultimate cause of $d u k k h a$ and argues that enlightenment requires extinguishing this illusion. On the other hand, Buddhists need to recognize that the illusion of self is at least highly useful if not essential for the survival and continued development of the human species. "The Buddhist can allow that the cognitive illusion of self is adaptive - it leads us to act to preserve ourselves as organisms and to raise our young" (Garfield 2018, 294). And, in any case, given that the illusion of self is a powerful illusion deeply rooted in our deepest wishes, in the structure of our language, in our social and narrative construction, and in the fundamental organization of the human brain as designed by natural selection, it is difficult to see how we can extinguish the illusion even if we would wish to do so. It is possible that we can change how it functions, but it is not at all clear that it is desirable or possible to make it disappear. "What of the future of this self illusion? It's unlikely to disappear.... One can speculate how changes will impact upon the individual's identity, but it would seem that in an ever more crowded future, we are going to need 
a pretty strong sense of self to survive" (Hood 2012, 296). We now need to consider how Buddhism envisions accomplishing the task of extinguishing the illusion of self, how it would have us develop a coherent and consistent no-self or, as I will explain shortly, non-self perspective required for the project of enlightenment.

\section{MINDFULNESS MEDITATION: SEEING THROUGH THE ILLUSION OF SELF AND THE NON-SELF PERSPECTIVE}

Extinguishing the illusion of self would require dispelling not just the attachment to the idea of self at the cognitive level but also the more primal appearance of self at the phenomenal level. Among other things, it would need to eliminate the first-person perspective. There would be no first-person perspective, because there would be no self inhabiting the person. Robert Wright has suggested that Buddhist enlightenment be termed "the view from nowhere" 17 and considers the following worry: "The view from nowhere...carries none of my selfish biases, or yours, and that in a certain sense isn't even a particularly human perspective, or the perspective of any other species. This, truly, would be a view that defied natural selection's authority, because natural selection is all about specific perspectives" (Wright 2017, 240). ${ }^{18}$ Thus, the no-self perspective is really the absence of a perspective that would draw a distinction between a first-person, second person, and third person perspective. It might, therefore, be better termed a "non-self perspective," and the development of such a perspective would seem to go against the evolutionary trajectory of our species. ${ }^{19}$ This non-self perspective, then, would transcend the perspective of what is good for me in opposition to what is good for you or even what is good for my species in opposition to other species. While Wright does not shy away from the problem of how it is possible to go against what human (and perhaps primate) evolution has built into our genome, he does suggest that opposing evolution at this stage of development may be precisely what we need to do, because "we've gotten to a point in human history where the sense of specialness could actually endanger the continued flourishing of human life" (Wright 2017, 242). Thus, although natural selection built into our species the illusion of self, we should not perpetuate the illusion and are not forced to do so, since "natural selection has also equipped us with tools for addressing the problem - rational and reflective faculties that in principle can transcend the circumstances of our birth" (Wright 2017, 245). Is

\footnotetext{
${ }^{17}$ Wright appropriates the phrase from the title of Thomas Nagel's book. Nagel uses the term to discuss the tension between the necessity of viewing things from a certain perspective and the ideal of objectivity which would transcend our particular viewpoint. See Nagel (1986).

${ }^{18}$ Of course, there would still be the organism's perspective of perceptual phenomena - I would still see the table from a certain spatial position - but it would lack a sense of the self viewing those phenomena and would, therefore, lack a sense of self-interest and self craving and attachment.

${ }^{19}$ It is probably the case that every sentient species has a perspective, and many of them might have a self-perspective, e.g., other primates. But it is unlikely that all or even most species have a selfperspective.
} 
this really possible? Buddhism claims to have developed such a tool in the form of mindfulness meditation, or vipassana $\overline{.}^{20}$

Vipassana $\bar{a}$ is a form of mindfulness meditation discussed in the Pāli Canon. It is aimed at seeing clearly and non-judgmentally the moment to moment phenomena for the purpose of insight into the nature of what we call our mind. It simply observes the passing thought, feeling, desire, intention, memory, emotion, etc., noting them each as they arise and disappear. In contrast to concentration meditation, which narrows the focus of attention to one object of consciousness, vipassana opens attention to the whole range of consciousness. It is important to emphasize that vipassana $\overline{\text { is not like }}$ ordinary awareness, attention, or introspection. "All consciousness involves awareness in the sense of a knowing or experiencing of an object. But with the practice of mindfulness [vipassanā] awareness is applied at a special pitch....[T] he mind is trained to remain in the present, open, quiet, and alert, contemplating the present event. All judgements and interpretations have to be suspended, or if they occur, just registered and dropped. The task is simply to note whatever comes up just as it is occurring, riding the changes of events in the way a surfer rides the waves on the sea" (Bodhi 1994, 7576). Vipassana practice makes it possible "to gain firsthand insight into how the mind constructs a seemingly stable reality out of the ever-changing flux of experience" (Siegel and Germer 2012, 30).

The first part of this articled surveyed the Buddhist arguments for the claim that there is no self. Although these arguments are important, I think that their primary importance lies in getting us to take the Buddhist doctrine of no-self seriously. The main assumptions on which these arguments are based - the impermanence claim, the claim that the psychophysical processes are not under our control, the exhaustiveness claim, and the claim of dependent origination - all require some verification in experience, and vipassanā provides a controlled way to verify the claims experientially. Through vipassan $\bar{a}$, one can observe the way mental processes arise as a result of other mental and bodily processes (verifying dependent origination), one can observe how rapidly these processes arise and disappear and are replaced by other mental process (verifying impermanence), and one can ultimately come to recognize that there is nothing behind these processes that can be called a self.

Buddhism, however, claims that vipassana can do more than simply corroborate the assumptions which ground the Buddhist arguments for no-self. Vipassanā can help us see how the illusion of self is constructed at the experiential level, why we are so attached to the idea of the self, why it is so difficult to give up the belief in the self, why there is a strong tendency to resist the arguments, and why the Buddhist idea of no-self seems so counter-intuitive. It can also more directly reveal that there is no self and how craving and grasping at the passing phenomena brings about suffering. "Mindfulness works like an electronic microscope....It sees the transitory and passing

\footnotetext{
${ }^{20}$ The term mindfulness (sati) is used both to refer to certain kinds of meditative practices and to the faculty which can be developed by those practices. As a faculty, it is the capacity to be receptively attentive to and aware of whatever is happening in the present moment. As a practice, the term

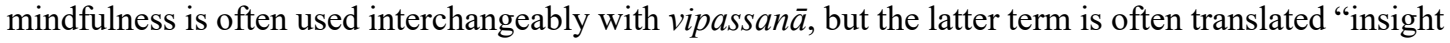
meditation."
} 
nature of everything that is perceived....It sees that there is no sense grabbing onto any of these passing shows....And finally, mindfulness sees the inherent selflessness of all phenomena" (Gunaratana 2015, 138). In doing this, vipassana also makes it possible to clearly see that that there is no inner CEO controlling the processes that we call our mind. "So if the conscious mind isn't in control, what is in control?...the answer may be: nothing in particular. The closer we look at the mind, the more it seems to consist of a lot of different players, players that sometimes collaborate but sometimes fight for control, with victory going to the one that is in some sense the strongest" (Wright 2017, 77).

Finally, Buddhism claims that if practiced sufficiently in conjunction with other Buddhist practices of the eight-fold path, vipassana can extinguish the illusion of self and create an abiding awareness of selflessness. ${ }^{21}$ "Given that the truth of impermanence serves as the main argument for the doctrine of selflessness, it should not surprise us that the active perception of arising and cessation is fundamental to this doctrine as well....[A] perception of the aggregates, their arising, and their passing away is explicitly said to trigger the attitude of selflessness" (Schulman 2014, 164). The result is that the Buddhist practitioner is now far along the path to enlightenment. The Buddhist practitioner now does not merely understand that the self is an illusion but has laid the foundation for a fully developed non-self perspective, a way of experiencing that is radically different from our ordinary first-person experience, and which radically transforms the way we relate to other persons, to nature, and to the world in general.

When one achieves a direct realization of emptiness and selflessness - very late on the path - one generates engaged bodhicitta, which is a completely impersonal commitment involving an experience of the world that does not represent a self at its center. Importantly, the difference between aspirational and engaged bodhicitta is characterized...by the mode of apprehension of selflessness. The difference is between an inferential, or merely cognitive, understanding and an immediate awareness of selflessness that frames experience (Garfield 2018, 286).

In other words, at the point of the path where one generates bodhicitta, even the phenomenal self is extinguished.

\footnotetext{
${ }^{21}$ Mindfulness, whose development requires vipassana $\bar{a}$, is only one of the components of the eight-fold path. The others are: right concentration, which is the other meditative discipline and also a component of vipassana ; right effort; right understanding, the philosophical discipline; right thought or intention, and the practices of good ethical conduct which are right speech, right action, right livelihood. Thus, for Buddhism, vipassana $\bar{a}$, even with the guidance of the philosophical arguments, cannot extinguish the illusion of self in the absence of the other components of the eight-fold path. This is because the full development of the awareness of selflessness is not just an experiential insight which corroborates the philosophical arguments but requires a radically different form of life, a transformation of one's whole way of being, a fundamental reorganization of ones habits and attitudes from selfish cravings, attachments, and aversions to compassionate concern for others. Thus, the Buddhist meditative disciplines cannot lead to a full awareness of selflessness without the consistent practice of the other components of the eight-fold path. In short, while vipassana provides the insight necessary for a nonself perspective, it is not sufficient.
} 


\section{IS IT POSSIBLE TO MAINTAIN A CONSISTENT NON-SELF PERSPECTIVE?}

I now want to return to the dilemma I posed earlier concerning the Buddhist soteriological project. Buddhist enlightenment would seem to require maintaining a coherent and consistent non-self perspective, as the enlightened individual has attained nirvana. ${ }^{22}$ To do so would seem to entail not just that we give up the philosophical idea of self as a metaphysical entity but that both the cognitive and the phenomenal sense of self are extinguished. On the cognitive level, this would entail that when we say the word "I", we do not essentialize or substantialize the indexical; that we do not think of our experiences as being owned by a unitary entity which is independent of those experiences, an entity which remains the same even as those experiences change; that when we think of ourselves as doing something now or in the past or the future, we do not assume an agent behind the processes which does, did, or will do those things; and we do not think that there is a fixed boundary between what is me and what is not me. So far, it does not seem improbable that vipassanā in conjunction with the other Buddhist practices could produce such a change in consciousness and mode of being, and this is already a fundamental change. However, what about the phenomenal sense of self? As a reminder: the phenomenal self in our species was constructed as an evolutionary necessity and is still encoded in our brains; it pulls together a multitude of experiences both synchronically and diachronically; it filters out brain processes that would otherwise overwhelm are us; it is elicited and turned on through our early childhood interactions with caretakers, and it is required for us to develop as social beings; it allow us to present ourselves to others as responsible persons; it is bound up with episodic memory and reinforced through narrative construction which gives these episodic memories a coherent structure with myself as the central character; and it constructs a model of myself in relation to a simulated model of the world that is necessary for successfully navigating social and physical reality. How, then, is it possible to act coherently, to plan and to choose effectively in the world without at least the sense of self at the phenomenal level?

In agreement with Buddhism, let us grant that vipassana $\bar{a}$, in conjunction with the other Buddhist practices elaborated by the eight-fold path, can produce a sense of selflessness that makes it possible to experience ourselves and the world in a radically

\footnotetext{
${ }^{22}$ Although I use the term "attaining Nirvana" as a convenient locution, I recognize that the expression can be misleading, as Nirvana is strictly speaking not something to be attained in any ordinary sense of the word. Rupert Gethin suggests that it is best understood as a verb rather than a noun, as in both Pāli and Sanskrit, "he attains nirvana" would best be rendered "he or she nirvana-s" or, if it describes the attainment after the death of the body, then "he or she paranirvana-s" (Gethin 1998, 75). Thus, Nirvana is not a place or a state of consciousness but the process by which the cravings and aversions are extinguished, by which the "fires" of the three poisons (greed/lust, hatred, and delusion) which bring about $d u k k h a$ are extinguished. What it is like to nirvana in a positive sense is described in such terms as the highest happiness, the ultimate reality, the unborn, the deathless, the breaking of the cycle of rebirth, the unconditioned, that which is beyond cause and effect, and this suggests that there is no way of really understanding what it is like to nirvana this side of enlightenment.
} 
different way. Let us grant that we can indeed develop a perspective which would entail that we no longer see ourselves as ontologically separate from others and that we no longer prioritize our own interests over those of others. However, let us also recognize that a consistent non-self perspective must include extinguishing not only the cognitive illusion of self but also the phenomenal illusion; and, given that we must interact with the natural and social world in a variety of ways, it is far from clear that it is possible to do this continuously without the phenomenal sense of self being at least sometimes operative.

Here is my hypothesis. Perhaps what happens as we move further along the path is that we oscillate between a non-self and a self-perspective in the same way that we oscillate between first seeing the illusion of the Kanizsa square, then, by careful attention, seeing that the square does not exist; and then, as we step back from our attentional focus, once again seeing the square even though we now know cognitively that it does not exist. Through the careful attention of vipassana, again in conjunction with other Buddhist practices, we can come to experience a sense of selflessness that can carry over and frame our experience outside of meditative practice for a time. However, even as we move considerably along the path to enlightenment and Nirvana, the sense of self returns at least at the phenomenal level, just as the Kanizsa square illusion returns when we step back from close attention to the spaces between any of the four black figures.

This hypotheses is at least partly supported by a sutta in the Samyutta Nikāya (85:3) that points out that, even when the seeker of enlightenment is no longer under the sway of sensual desires, even when there is a clear awareness that the aggregates are impermanent and not self, a subtle sense of "I am" remains. In this discourse, Khemaka, a disciple of the Buddha who is perhaps at the penultimate stage of the path, is approached by a number of other disciples who ask him whether he sees anything of the self in the five aggregates; and when he declares no, they declare that he must be an arahant, one whose taints are destroyed..$^{23}$ To this he replies that he is still not an arahant, since the sense of "I am" has not yet vanished even though he does not regard any of the aggregates as "This I am." He then compares his situation to that of a cloth which, after being soiled and stained, has been extensively cleaned by a laundryman but which still retains "a residual smell of cleaning salt, lye or cowdung that has not yet vanished."

"So too, friends, even though a noble disciple has abandoned the five lower fetters, still in relation to the five aggregates subject to clinging, there lingers in him a residual conceit ' $I$ am,' a desire 'I am,' and an underlying tendency 'I am' that has not yet been uprooted." (Bodhi 2000, 945).

It is not clear from this sutta whether or not Khemaka experiences the taint of "I am" continuously throughout his daily experience. However, it is likely that at least when

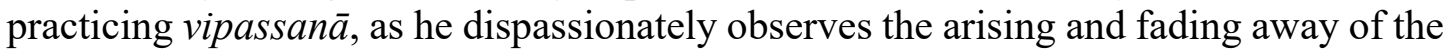

\footnotetext{
${ }^{23}$ In early Buddhism, the arahant is a human being who is fully enlightened, who has attained Nirvana.
} 
aggregates, his phenomenal sense of self disappears, and perhaps even remains suppressed for a time as he continues to cultivate mindfulness outside of formal meditation. At least this is my experience in practicing vipassanā, and I am nowhere near the penultimate stage of the path that Khemaka had reached. Thus, it seems likely that those on the path to enlightenment will oscillate between a non-self and a self perspective and that, as one comes closer to enlightenment, the self perspective takes a more subtle phenomenal form.

Still, the question remains, what happens when those on the path finally become enlightened, what happens when Nirvana is finally attained? This same sutta does have an answer to this. Khemaka concludes that as he "dwells thus contemplating the rise and fall of the aggregates....the underlying tendency 'I am' that had not been uprooted - this comes to be uprooted" (Bodhi 2000, 945). And the sutta concludes with Khemaka and his listeners all becoming enlightened. If we take this as the decisive Buddhist answer, it means that for the fully enlightened person even the most subtle phenomenal sense of "I am" is finally extinguished and will not return. Thus, it would seem that, at least for the classical early Buddhist position, those who are fully enlightened can maintain a consistent non-self perspective. While it would be presumptuous of me on this side of enlightenment to insist that this is incorrect, I do think that there are some reasons to doubt that the phenomenal sense of self can be permanently extinguished even for fully enlightened individuals, at least as long as they remain living human beings. ${ }^{24}$

To make the problem clearer, let us consider more carefully what happens in the Kanizsa square illusion. The Kanizsa square is a completion illusion in which our brain/mind fills in what is not there in order to create a coherent perceptual structure. However, by careful attention and examination, we can come to see that there are no lines between the black figures. Still, the moment we step back from such attentive examination, the mind once again projects the square onto the four figures even though we now know that there is, in fact, no square. If we again closely examine the spaces between the black figures, we can once again see that the appearance of the square is an illusion. Thus, we can oscillate between seeing the illusion of the square and seeing that there is no square. This is not, however, a Gestalt switch. The oscillation between seeing the square and, through careful attention, seeing that there is no square is not like the oscillation between seeing the same figure first as a duck and then as a rabbit; or the switch from seeing the same figure first as two faces and then as a goblet. ${ }^{25}$ In a Gestalt switch illusion, while we can only see one image at a time, we can choose, through focusing on certain parts of the figure, which image appears. However, with the Kanizsa square illusion, it is not a question of choice. When we step back from the careful examination of what is between each of the four figures and look again at the

\footnotetext{
${ }^{24}$ Buddhism distinguishes between Nirvana with residue remaining and Nirvana without residue remaining. The former is the attainment of Nirvana in one's lifetime, and the residue that remains is the residue of the five aggregates which continue to exist even after the poisons of greed/lust, hatred, and delusion have been extinguished. The latter refers to Nirvana after death.

${ }^{25} \mathrm{I}$ am indebted to Kin Cheung for pointing out the distinction between a replacement illusion and a Gestalt switch illusion.
} 
drawing as a whole, the square necessarily reappears. The necessity is built into the way our perceptual-neural system is organized. ${ }^{26}$

In an analogous way, our phenomenal sense of self is the result of the way our neuro-psychological system is organized, an organization which, while initially elicited in the course of our early childhood interactions with parents or other caretakers and which is bound up with episodic memory and reinforced through narrative construction, is embedded in our genome. Of course, there are ways in which the Kanizsa square and the phenomenal sense of self are not analogous. Through vipassana $\bar{a}$, we can at least for a time dismantle or suspend the phenomenal illusion of self, while, at least for me, it is not possible to suspend the illusion of the square if I look at the entire figure. Nevertheless, it is more than likely that even when one has become fully enlightened, the phenomenal sense of self returns periodically, because it is needed for certain practical functions. There are, I think, several reasons for this. The first is that enlightened human beings are still human beings with a human genome, and their brains are still organized by the imperatives of that genome which include: coordination of sensory data into perceptions of objects; ways of structuring experience to distinguish themselves from those objects and also to distinguish themselves from other persons (with an assist from their early childhood social interactions); and coordination of multiple brain processes and experiences to form thoughts, emotions, and intentions that will make it possible for them to plan, make choices, and act effectively in the world. The way the human brain is naturally organized to do this employs the device of the phenomenal self. Could the Buddha have planned and organized a monastic order without such a device?

The second reason is that episodic memories and narrative construction are essential for a human understanding of our relation to the past; and to remember something is to remember something that I did or that happened to me; and to tell a story about my life is to put myself in the center of the story. It is of no small consequence that persons who are considered enlightened also talk about their lives in narrative form, and, in fact, some of them have even written autobiographies. For example, the Dalai Lama has written two autobiographical books, the most recent of which is entitled Freedom in Exile: the Autobiography of the Dalai Lama (2008). He surely could not have done so without having his episodic memory pieced together by a narrative sense of self. Of course, we might argue that perhaps the Dalai Lama is not fully enlightened. However, if full enlightenment is possible, then the Buddha was enlightened; and while the Buddha never wrote an autobiography, he certainly told his followers many stories about his life before he attained Nirvana, and he even claims to have remembered his past lives. In short, he communicated with his followers in part by constructing a narrative of his life in which he was the central character.

\footnotetext{
${ }^{26}$ It has been suggested to me by more than one person that it is possible to see the Kanizsa illusion as four black Pac-Men about to attack each other. I think, however, that this is a conceptual move rather than a perceptual seeing. However, even allowing that it is a perceptual seeing, it is only possible for me even to begin to see the figures this way by focusing only on two adjacent figures at a time and by ignoring the four figures as a whole. I would ask the reader to look at the Kanizsa square illusion again and determine if her experience is really different than mine.
} 
The third reason for thinking that even those who have become enlightened would at least periodically experience a phenomenal self is that it is a necessity for many kinds of social interactions in which they need to engage. The Buddha, as described in the Nikāyas, entered into many different kinds of dialogues with others to teach and explain the Dharma. In these dialogues, he taught the Dharma in very different ways, often using skillful means (upāya) to address different individuals according to their level of development. The Buddha also used speech in a mindful way (right speech), which means not just that what he said was truthful but that when he spoke, he did so compassionately and kindly, taking into account the specific needs and sensitivities of his listeners. All this required an empathetic understanding of the other, and empathy requires some way of distinguishing oneself from the other. ${ }^{27}$ Given that the Buddha was still a human being with a human genome, the most likely device that enabled him to do this was the phenomenal appearance of the self.

Finally, the Buddha also knew how to navigate non-human reality. He must have known how to avoid stepping on snakes and eating poison mushrooms, how to keep warm, and find food in the forest, and, in general, once he developed the understanding of the "middle way" between the extremes of asceticism and hedonism, he did what was necessary to protect his body from harm and to remain physically healthy. While many animals can do this by instinct, human beings do this by generating a world simulation model and an image of self in relation to that world model, and this requires drawing some boundary line between what is oneself and what is "out there;" in effect, it requires experiencing oneself as a subject in relation to objects and non-human animals in the natural world. This is not to deny that this boundary line is an illusion, and clearly the Buddha would have recognized that it is an illusion, but simply to point out that it is sometimes necessary to utilize this illusion not only for ordinary human beings but even for buddhas. In all, it is highly likely that even enlightened persons, because they are still human beings, will oscillate between a non-self perspective and a phenomenal self perspective; although they, in contrast to those still on the path, may have more choice in when to allow the illusion of self to reappear and when to allow it to disappear.

Once again, it would be presumptuous of me on this side of enlightenment to claim that I know that those who are enlightened would not be able to maintain a non-self perspective continuously. However, I want to put to rest a worry that if my hypothesis is correct, then enlightenment is not possible. That even those who have attained Nirvana might not be able to maintain a non-self perspective at all times does not entail that they cannot consistently think and act in fundamentally selfless ways. I would agree with Evan Thompson when he argues that "enlightenment" or 'liberation'...doesn't consist in dismantling our constructed sense of self, as may happen in certain meditative states. Rather, it consists in wisdom that includes not being

${ }^{27}$ Amy Coplan argues that one of the criteria for empathy is a sense of self, because in order to adopt the perspective of the other I must recognize that the other is separate from myself. She proposes the following definition: "empathy is a complex imaginative process in which an observer simulates another person's situated psychological states while maintaining clear self-other differentiation" (Coplan 2011, $5)$. 
taken in by the appearance of the self as having independent existence while that appearance is nonetheless still there and performing its important I-making function" (Thompson 2015, 366). Thus, enlightenment would be possible even if the phenomenal sense of self never entirely disappears. Thompson, however, seems to suggest that the appearance of self on the phenomenal level is only occasionally dismantled in certain meditative states and that this may not be very significant, because he takes the phenomenal sense of self, although constructed, as real in an important sense; whereas I regard the appearance of the phenomenal self as an illusion. This is a difference which, for reasons of space, I shall not attempt to discuss here. ${ }^{28} \mathrm{I}$ do, however, want to reiterate that whatever the ontological status of the phenomenal self, I think that there is ample evidence (my own experience included) that intense vipassanā practice can extinguish the phenomenal appearance of self in a way that can sometimes carry over beyond formal meditation. Extrapolating from this, it is highly likely that fully enlightened individuals can dismantle and extinguish the phenomenal self continuously in deep meditation and that, by being receptively attentive outside meditation, they can often maintain a non-self perspective for a considerable period of time. If this is correct, then it is only when enlightened individuals are engaged in particular kinds of activities that require the phenomenal sense of self that they will need to return temporarily to a self perspective.

However, because they are enlightened, when the phenomenal illusion of self reappears, they would still always recognize that it is an illusion not just cognitively but affectively. They would not be entranced by or attached to the illusion of self in the same way that once we understand how the magic trick works, it no longer enchants us. ${ }^{29}$ Thus, the cravings and aversions and the poisons of greed/lust, hatred, and delusion would remain extinguished. When enlightened human beings need to interact with other persons or with the other parts of the natural world in ways that require a self perspective, they could employ the phenomenal self the way someone might play monopoly without attachment to winning, recognizing that it is only a game, and knowing that the money in the game is not real. ${ }^{30}$ In short, they could employ the phenomenal illusion of self without falling under its spell. Thus, those who are enlightened can mindfully allow the self perspective to reappear and continue to act with loving kindness, compassion, sympathetic joy, and equanimity. And, like the Buddha, they could also find time for long solitary meditation retreats during the year

\footnotetext{
${ }^{28}$ The discussion would require my going into an analysis of Buddhist reductionism, which Thompson rejects and which I think is plausible, and a consideration of his claim that the constructed self has a dynamic organization which is not reducible to its component parts.

29 "Just as uncovering a magician's trick makes it impossible to keep on being fooled by it, lifting the veil of identification will make it impossible to be fooled by its content of self-identity" (Albahari 2013, 104).

${ }^{30}$ I am indebted to Christopher Gowans for this analogy. In fact, the enlightened person would, if necessary, play the economic game of earning and spending "real" money without being attached to it and knowing that money is a social convention that has no intrinsic nature.
} 
and take time to meditate during a part of each day when they could dispel completely even the phenomenal illusion of self. ${ }^{31}$

\section{ACKNOWLEDGEMENTS}

I am thankful to anonymous reviewers of this journal for their helpful comments and substantial suggestions for revising this article.

\section{REFERENCES}

Albahari, Miri (2013), "Nirvana and Ownerless Consciousness," in Mark Siderits, Evan Thompson, and Dan Zahavi (eds.), Self, No Self? Perspectives from Analytical, Phenomenological, and Indian Traditions (Oxford, UK: Oxford University Press), 104-113.

Batchelor, Stephen (2011), Confessions of a Buddhist Atheist (New York: Spiegel and Grau).

Bodhi, Bhikkhu (1994), The Noble Eightfold Path: The Way to the End of Suffering (Onalaska, WA: British Publication Society).

Bodhi, Bhikkhu (2000), The Collected Discourse of the Buddha: a New Translation of the Samyutta Nikāya, trans. Bhikkhu Bodhi (Somerville, Massachusetts: Wisdom Publications).

Coplan, Amy (2011), "Understanding Empathy: Its Features and Effects." in Amy Coplan and Peter Goldie (eds.), Empathy: Philosophical and Psychological Perspectives (Oxford, UK: Oxford University Press), 2-18.

Dalai Lama [Tenzin Gyatso] (2008). Freedom in Exile: the Autobiography of the Dalai Lama (New York: HarperPerrenial).

Dennett, Daniel C. (1992), "The Self as a Center of Narrative Gravity", in Frank S. Kessel, Pamela M. Cole, and Dale L. Johnson (eds.), Self and Consciousness: Multiple Perspectives (Hillsdale, New Jersey: Lawrence Erlbaum Associates), 103115.

Freud, Sigmund (1989), The Future of an Illusion, trans. James Strachey (New York: W.W. Norton and Co.).

Garfield, Jay L. (2015), Engaging Buddhism: Why it Matters to Philosophy (New York: Oxford University Press).

Garfield, Jay; Nichols, Shaun; and Strohminger, Nichols (2018), "Episodic Memory and Oneness", in Philip J. Ivanhoe, Owen J. Flanagan, Victoria S. Harrison, Hagop Sarkissian, and Eric Schwitzgebel (eds.), The Oneness Hypothesis: Beyond the Boundary of Self (New York: Columbia University Press), 285-304.

\footnotetext{
${ }^{31}$ It is said that the Buddha would leave his sangha for solitary meditative retreats for three months of every year and that he would spend a part of each day alone in meditation.
} 
Gethin, Rupert (1998), The Foundations of Buddhism (New York: Oxford University Press).

Gunaratana, Bhante Henepola (2015), Mindfulness in Plain English, 20 ${ }^{\text {th }}$ anniversary edition (Somerville, Massachusetts: Wisdom Publications).

Hood, Bruce (2012), The Self Illusion: How the Social Brain Creates Identity (New York: Oxford University Press).

Mead, George H. (1963) Mind, Self, and Society, ed. Charles W. Morris (Chicago: The University of Chicago Press).

Metzinger, Thomas (2009), The Ego Tunnel: The Science of the Mind and the Myth of the Self (New York: Basic Books).

Nagel, Thomas (1989), The View from Nowhere (New York: Oxford University Press).

Olendzki, Andrew (2016), Untangling Self: A Buddhist Investigation of Who We Really Are (Somerville, Massachusetts: Wisdom Publications).

Rahula, Walpola (1959; $2^{\text {nd }}$ edition 1974), What the Buddha Taught (New York: Grove Press).

Shulman, Eviatar (2014), Rethinking the Buddha: Early Buddhist Philosophy as Meditative (New York: Cambridge University Press).

Siderits, Mark (2003; $2^{\text {nd }}$ edition 2015), Personal Identity and Buddhist Philosophy: Empty Persons (Burlington, Vermont: Ashgate Publishing Company).

Siegel, Ronald D. and Germer, Christopher K. (2012), "Wisdom and Compassion: Two Wings of a Bird," in Christopher K. Germer and Ronald D. Siegel (eds.), Wisdom and Compassion in Psychotherapy: Deepening Mindfulness in Clinical Practice (New York: The Guilford Press, 2012), 7-34.

Thompson, Evan (2015), Waking, Dreaming, Being: Self and Consciousness in Neuroscience, Meditation, and Philosophy (New York: Columbia University Press).

Wright, Robert (2017), Why Buddhism is True: The Science and Philosophy of Meditation and Enlightenment (New York: Simon and Schuster). 